\title{
Quando trincheiras de ideias valem mais que trincheiras de pedras: combates de ideias entre dois líderes das independências hispano-americanas
}

Eugênio Rezende de Carvalho*

FREDRIGO, Fabiana de Souza. Guerras de papel: Francisco de Paula Santander e Simón Bolívar, das peças autobiográficas à relação epistolar (1826-1837). Goiânia: Editora UFG, 2017. 320p.

Com a passagem de dois séculos desde a deflagração, em 1810, dos processos históricos que se estenderam até 1824 e culminaram na emancipação das colônias hispano-americanas, vêm ocorrendo em vários países da América Latina "celebrações" do bicentenário de suas respectivas independências políticas. Por meio dessas efemérides, os calendários acabam nos impondo, periodicamente, seus temas e fatos históricos de forma implacável, fornecendo sempre, felizmente, a possibilidade de um novo olhar para um "mesmo" passado. Na esteira dessas celebrações, o grande público de cada uma dessas nações tem tido e terá à disposição, certamente, um acesso maior às sínteses históricas, cronológicas e factuais a respeito das independências nacionais. Surge, assim, a oportunidade, embora menor do que se poderia esperar, para o necessário debate sobre o significado, em pleno século XXI, desses acontecimentos que marcaram indelevelmente os perfis, os limites e as possibilidades de novos Estados nacionais latino-americanos que começariam a ser formados a partir das primeiras décadas do século XIX, quando a própria ideia de América Latina sequer existia.

Além do mais, é natural que tal efeméride alcance e instigue ainda o debate acadêmico e a prática historiográfica, desafiando os historiadores da região a revisitar o tema, empreender seus balanços e, eventualmente, reavaliar e reconsiderar tradicionais interpretações acerca de tais processos históricos, dos seus limites e complexidades, das principais ideias ou circunstâncias que lhes serviram de motivação, bem como do papel desempenhado pelos seus principais agentes e sujeitos, individuais ou coletivos - seja à

\footnotetext{
Professor Titular da Faculdade de História e do Programa de Pós-graduação em História da Universidade Federal de Goiás (UFG), Brasil. Pesquisador Bolsista Produtividade do CNPq, com atuação e experiência nas áreas de História das Américas - especialmente América Latina - e de Teoria e Filosofia da História. E-mail: eugeniodecarvalho@gmail.com
}

\section{CANPHLAC}

Revista Eletrônica da ANPHLAC, ISSN 1679-1061, №. 24, p. 319-323, Jan./Jun., 2018.

http://revista.anphlac.org.br 
luz de novas fontes ou com base em novos olhares, novas abordagens ou perspectivas teórico-metodológicas. É neste contexto que se insere e se desenvolve a pesquisa que deu origem ao livro Guerras de papel: Francisco de Paula Santander e Simón Bolívar, das peças autobiográficas à relação epistolar (1826-1837), de Fabiana de Souza Fredrigo, professora e pesquisadora latino-americanista da Faculdade de História e do Programa de Pós-graduação em História da Universidade Federal de Goiás (UFG).

Esse livro, conforme relata a própria autora, apresenta-se como uma continuidade de um esforço investigativo iniciado com a elaboração de sua tese de doutoramento, na qual explorou o tema História e memória no epistolário bolivariano (1799-1830), defendida na UNESP-Franca em 2005 e publicada na forma de livro em $2010^{1}$. Essa temática fora mais tarde aprofundada e estendida em sua pesquisa de pósdoutoramento, concluída em 2010 junto à Universidade de São Paulo (USP), da qual resultou o livro que ora resenho. Nele, a autora se propôs a ler e reavaliar, à luz da historiografia, as cartas de Francisco de Paula Santander (1792-1840), confrontando-as com as epístolas de Simón Bolívar (1783-1830), de forma a indicar a formação de uma rede de sociabilidade entre esses generais independentistas hispano-americanos, incorporando ainda as peças autobiográficas de Santander ao seu estudo, de forma a enriquecê-lo mediante o diálogo entre as fontes de natureza autobiográfica e epistolar.

Assim, segundo Fredrigo, o objetivo principal de Guerras de papel foi cotejar a correspondência de Bolívar com a de Santander, considerando que as versões históricas em torno da independência e dos homens que nela atuaram foram construídas a partir de Bolívar. Visando tal objetivo, a autora se empenhou em construir parte da rede de correspondência entre Bolívar e seu mais importante interlocutor, Santander, por meio da leitura e da avaliação do epistolário deste último, compreendendo ser possível, a partir dessa fonte - somada às peças autobiográficas de Santander - "propor novas discussões em torno dos projetos nacionais para as Américas e, sobretudo, indicar as disputas de memória internas à elite latino-americana, condutora do processo das independências no século XIX” (FREDRIGO, 2017, p. 18).

Guerras de papel encontra-se dividido em duas partes ou capítulos. O primeiro, intitulado $O$ ato autobiográfico: o combate de Francisco de Paula Santander, trata da 1 FREDRIGO, Fabiana de Souza. Guerras e escritas: a correspondência de Simón Bolívar (1799-1830).
São Paulo: Editora UNESP, 2010. 290p.

\section{GANPHLAC}

Revista Eletrônica da ANPHLAC, ISSN 1679-1061, №. 24, p. 319-323, Jan./Jun., 2018.

http://revista.anphlac.org.br 
apresentação e análise das peças autobiográficas de Santander escritas em 1829 e em 1837, indicando de que maneira Bolívar funcionaria como uma "persona-espelho" para a escritura autobiográfica, colaborando para "afirmar a existência de uma comunidade de valores entre os generais independentistas" (2017, p. 295). Libertar e organizar a América desejada: diferentes acepções na correspondência entre Francisco de Paula Santander e Simón Bolívar é o título do segundo capítulo, que trata pormenorizadamente da correspondência entre Santander e Bolívar, no período entre 1826 e 1830, com destaque para as divergências entre os dois generais independentistas, que tiveram como fruto, conforme Fredrigo, uma redefinição dos significados de libertar e organizar. Cada um desses capítulos subdivide-se em cinco itens, procurando, segundo a autora, expor as reflexões pertinentes às fontes utilizadas e ao tema de seu interesse, qual seja, as independências na América Hispânica. A ordem desses capítulos e seus temas justificam-se, de acordo com Fredrigo, por permitir desvelar, primeiro, como o escrito autobiográfico explorava as cartas para, depois, apresentá-las. Em seu esforço de se afastar de certas interpretações historiográficas tradicionais, a autora, com sucesso, não se limitou a registrar o histórico de desentendimentos entre os dois generais, antigos companheiros; buscou qualificá-lo e, sobretudo, demonstrar que tais dissonâncias se constituíam sobremaneira pelo "ressentimento (e partilha, efetivamente) quanto a um projeto para a América" (FREDRIGO, 2017, p. 25).

Ampliando e avançando os propósitos de sua tese de doutorado, de posse de um rico e variado conjunto de fontes sobre o tema estudado e ainda lançando mão de um apurado rigor teórico-metodológico em sua análise, o texto de Fabiana Fredrigo explora com ousadia novos territórios disciplinares (psicanálise, linguística e crítica literária), ampliando notavelmente o horizonte de sua reflexão, buscando escapar das abordagens historiográficas que privilegiam em demasia as estruturas políticas e/ou econômicas ou que corroboram a tese da ineficácia transformadora da elite criolla, abordagens essas insuficientes e incapazes - como acertadamente aponta a autora - de explicar a complexidade dos processos históricos das independências hispano-americanas. Logra com isso, em relação ao diálogo entre os generais hispano-americanos Bolívar e Santander, a "demonstração da partilha de um projeto americano, sustentado pela ação na guerra e na política" (2017, p. 294), revelando o que Fredrigo chama de uma "cultura heroica", reforçada pelas histórias nacionais do século XIX. De sua investigação,

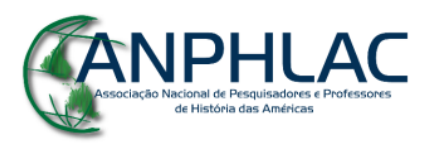

Revista Eletrônica da ANPHLAC, ISSN 1679-1061, №. 24, p. 319-323, Jan./Jun., 2018.

http://revista.anphlac.org.br 
decorre uma crítica à tese reducionista segundo a qual "à elite criolla interessava tão somente ocupar o lugar de comando dos espanhóis" (embora reconheça que esse tenha sido um dos interesses), enfatizando a necessidade de se explicar a complexa dinâmica das ideias de Bolívar e Santander, que iam do otimismo, esperança e mudança à frustração e perplexidade (FREDRIGO, 2017, p. 296).

A propósito, ao longo das páginas de Guerras de papel, o leitor terá a oportunidade de conhecer a perspectiva crítica da autora sobre parte da história política tradicional, que trata dos processos das independências hispano-americanas, cuja narrativa historiográfica teria se concentrado nos interesses criollos para efetivar a independência. Fredrigo propõe uma inversão da questão colocada por essa narrativa tradicional, deslocando o foco para a identificação e análise das dificuldades inesperadas, do imponderável, das frustrações de Bolívar e Santander. Como diferenças fundamentais que motivavam as guerras de papel entre os principais líderes do processo independentista, encontravam-se os distintos projetos de republicanismo que cada um deles preconizava. Vale sublinhar que tais combates deram-se sob a égide de uma forte tradição discursiva detratora e preconceituosa, de origem europeia e de remotas raízes históricas, que, no afã de descrever a realidade americana, incluindo sua natureza e sua gente, desqualificava o Novo Mundo a partir de argumentos (acusações) como impotência, inferioridade e degeneração. Trata-se do fenômeno que o historiador das ideias italiano Antonello Gerbi, em seu clássico O Novo Mundo: história de uma polêmica (1750-1900), chamou de “calúnia” contra a América. É nesse sentido que, conforme a autora registra com precisão, essa geração da independência teve de lidar com "o dilema de ter de ser americana, quando os parâmetros de civilidade impostos eram os europeus. Os americanos tiveram de se descobrir e se refazer americanos" (FREDRIGO, 2017, p. 27). É igualmente nessa perspectiva que Fredrigo chama ainda a atenção para o desconforto e ressentimento manifestados por Bolívar e Santander "com a obra das independências, não exatamente pela separação da Espanha, mas pela frustração não prevista em relação a uma modernidade que, àqueles olhos (pese o otimismo de outros tempos), era inalcançável" (2017, p. 31).

Por fim, da perspectiva do historiador - e não do linguista - , atenta à historicidade dos discursos, à tensão entre as fontes e o debate historiográfico, aos limites da subjetividade e da objetividade, aos códigos internos e externos à linguagem,

\section{GANPHLAC}


Fabiana de Souza Fredrigo estabelece, em Guerras de papel, "relações entre a escrita da história, a leitura do epistolário e a narrativa interna às cartas e às peças autobiográficas" (2017, p. 36). Suas fontes privilegiadas, autobiografias e cartas, colocam em evidência a dimensão da vida privada, sempre entremeada à vida pública, de dois generais independentistas; oferecem um contraponto, ou complemento, a tantos documentos públicos por eles produzidos, brindando-nos, assim, com outra face, notadamente subjetiva e privada, dos "heróis" das independências. Além disso, em Guerras de papel encontramos uma rica discussão e análise acerca das relações entre as independências e a liberdade, sobre como aquelas não garantiram esta, ao contrário do que desejaram Bolívar e Santander no contexto das independências hispano-americanas. Uma discussão que abrange e se articula, vale dizer, à outra complexa e problemática relação: entre as independências e os projetos de identidade nacional propugnados pelas lideranças dos movimentos independentistas.

Para concluir, retomo e justifico o título conferido a esta resenha, evocando um intelectual, escritor e líder político cubano do século XIX, José Julián Martí y Pérez (1853-1895), que tal como Santander e Bolívar - e inspirado em grande parte por este último - também lutou pela independência de sua pátria contra o domínio espanhol. Martí, certa vez, escreveu que uma trincheira de ideias vale mais que uma trincheira de pedras. Tal máxima poderia ser aplicada com bastante propriedade ao caso dos generais independentistas Bolívar e Santander, que combateram as suas guerras - juntos ou entre si -, valendo-se de suas espadas, mas, fundamentalmente, de suas penas. Enfim, combateram escrevendo; suas artilharias eram compostas sobretudo por ideias. Daí ter concluído a própria autora, de forma feliz e acertada, que seu livro "Guerras de papel é a expressão de um combate tão vivaz e fundamental quanto o que teve lugar nos campos de luta contra o exército espanhol" (FREDRIGO, 2017, p. 295). Numa analogia com tal assertiva, extrapolando-a, arriscamo-nos a dizer, em outra dimensão, que Guerras de papel pode ser, ele próprio, a expressão do combate vivaz e fundamental pela renovação da historiografia acerca tanto dos processos e movimentos de independência política das colônias espanholas na América quanto do pensamento político hispano-americano do século XIX.

\section{GANPHLAC}

